\title{
Recall of short word lists presented visually at fast rates: Effects of phonological similarity and word length
}

\author{
VERONIKA COLTHEART and ROBYN LANGDON \\ Macquarie University, North Ryde, New South Wales, Australia
}

\begin{abstract}
Phonological similarity of visually presented list items impairs short-term serial recall. Lists of long words are also recalled less accurately than are lists of short words. These results have been attributed to phonological recoding and rehearsal. If subjects articulate irrelevant words during list presentation, both phonological similarity and word length effects are abolished. Experiments 1 and 2 examined effects of phonological similarity and recall instructions on recall of lists shown at fast rates (from one item per 0.114-0.50 sec), which might not permit phonological encoding and rehearsal. In Experiment 3 , recall instructions and word length were manipulated using fast presentation rates. Both phonological similarity and word length effects were observed, and they were not dependent on recall instructions. Experiments 4 and 5 investigated the effects of irrelevant concurrent articulation on lists shown at fast rates. Both phonological similarity and word length effects were removed by concurrent articulation, as they were with slow presentation rates.
\end{abstract}

A large body of memory research during the past 40 years has shown limits on our ability to recall short lists of unrelated letters, digits, words, and objects when these lists are presented at a rate of around $1 \mathrm{sec}$ per item and when the list must be recalled in order of presentation. During the 1960s, several theories postulated the existence of a short-term memory store with a rehearsal process as the memory system supporting retention of briefly presented stimuli (Atkinson \& Shiffrin, 1968; Waugh \& Norman, 1965). Subsequent research by Baddeley and his colleagues led to the formulation of an influential theory of short-term working memory consisting of a central executive system served by two slave systems: the visuospatial sketchpad and the phonological loop (Baddeley, 1986). The phonological loop, which consists of a phonological short-term store and an articulatory/ phonological rehearsal process, is the system used for the recall of rapidly presented lists. According to this theoretical account, spoken items gain obligatory and direct access to the phonological short-term store. Visually presented items gain access to the phonological short-term store after they have been phonologically recoded (in the case of written words) or after their names have been retrieved (in the case of objects or pictures of them). Since the phonological short-term store is viewed as limited in capacity and

The research reported in this paper was supported by an ARC grant to V.C. The authors thank Max Coltheart for useful discussion of a draft of this paper and G. Loftus and A. Healy for their suggestions. Correspondence should be sent to V. Coltheart, Psychology Department, School of Behavioural Sciences, Macquarie University, North Ryde, NSW 2109, Australia (e-mail: veronika.coltheart@mq.edu.au).

-Accepted by previous editor, Geoffrey R. Loftus duration, memory traces must be maintained and refreshed by rehearsal. Evidence consistent with this theoretical account consists of the following frequently replicated findings.

\section{The Phonological Similarity Effect}

Lists of phonologically similar items (letters, words, or pictures with similar names) are recalled less accurately than are lists of dissimilar items (e.g., Baddeley, 1966; Schiano \& Watkins, 1981; Wickelgren, 1965). This phonological similarity effect is removed by concurrent articulation when lists are presented visually (e.g., Coltheart, 1993a; Murray, 1968). In the concurrent articulation condition, subjects are required to engage in repetitive, irrelevant speech (saying "the, the, the,..." or " $1,2,3,4,5,1,2,3,4,5, \ldots$ ) during list presentation. Baddeley (1986) proposed that concurrent articulation disrupts both phonological recoding and rehearsal. Given that, with auditory presentation, the phonological similarity effect survives concurrent articulation, Baddeley (1986) argued that the locus of the phonological similarity effect is phonological short-term store and that concurrent articulation has prevented access of visual items to this store.

\section{The Word Length Effect}

Another frequently replicated result is the finding that lists of short words are better recalled than are lists of long words (Baddeley, Thomson, \& Buchanan, 1975; Coltheart, Avons, \& Trollope, 1990). This word length effect is removed by concurrent articulation for both visually and auditorily presented lists. Memory performance is correlated with speech rate for the list words. Consequently, Baddeley (1986) argued that the word length ef- 
fect arises from limits on the capacity of the rehearsal loop. Fewer long words than short words can be accommodated in the rehearsal loop. There has been some debate over whether the relevant variable is the number of phonemes/ syllables or whether the duration of the utterance causes this effect (Baddeley \& Andrade, 1994; Caplan \& Waters, 1994). However, it is clear that when the words in a list have many phonemes and syllables, they will be less well recalled than will words consisting of few phonemes and syllables.

\section{Effects of Concurrent Articulation}

The rehearsal process, formerly termed articulatory rehearsal, was assumed to involve articulatory mechanisms and to take place in real time at a rate comparable to that of overt speech. Evidence for this view of rehearsal comes from attempts at measuring overt speech rate for the words used to constitute short- and long-word lists. Speech rate has typically been measured by timing speeded repeated articulations of the words used in the memory tasks (Baddeley et al., 1975). A further assumption has been the notion that covert speech proceeds at the same rate as overt speech, and this view appears to depend on the results of a single paper by Landauer (1962). Later studies by Anderson (1982), MacKay (1981), and Marshall and Cartwright $(1978,1980)$ all found that inner speech is faster than overt speech. The difference between the two rates seems to be of the order of $15 \%-25 \%$. The idea that the rehearsal loop's capacity is equivalent to the amount of speech that can be articulated in 1.5-2 sec appears to arise from the finding of a significant positive correlation between speech rate and memory span (Baddeley et al., 1975), but such correlations do not imply that the rates are equal.

\section{Retention Measures}

Use of probed recall techniques has led to questions about the role of rehearsal in mediating both phonological similarity and word length effects on serial recall (Avons, Wright, \& Pammer, 1994; Henry, 1991). Using concurrent articulation during auditory list presentation and serial or probed recall, Avons et al. found word length effects with both types of recall task. The word length effect also occurred with probed recall tasks when word lists were presented visually (in the absence of concurrent articulation). They concluded that word length effects may arise during output: through decay, limits on capacity, or output interference in an output buffer.

\section{List Composition}

From the earliest phase of research on short-term memory, the practice was to use a small set of list items from which lists were chosen. This procedure was introduced by Conrad (1964) and subsequently used by Baddeley (1966) in virtually all the studies that followed. In Baddeley's (1966) experiments, sets of 8 or 10 words were used ( 8 or 10 phonologically similar words and 8 or 10 phonologically dissimilar words), and lists were repeat- edly sampled from these small word sets. Furthermore, the subjects were familiarized with these word sets, which were, in some experiments, visible throughout the task. The rationale, occasionally mentioned, seems to have been the assumption that short-term working memory is specialized for the encoding of order information and that demands of item encoding should be minimized. In some experiments, the task is reduced to no more than the requirement to recall a set of the same 5 items in varying orders (Baddeley et al., 1975, Experiment 5). Clearly, this list feature severely restricts the conclusions that can be drawn from the findings. It means that what we can say about short-term memory tasks applies to situations in which the same small set of items must repeatedly be recalled in different orders. The view that recall of order is crucial to the phonological similarity effect seems to be based on the reports by Wickelgren (1965) and Watkins, Watkins, and Crowder (1974) that, if item order is disregarded, the number of items recalled does not differ for phonologically similar and dissimilar lists. However, subsequently, Schiano and Watkins (1981), who presented word and picture lists, found both phonological similarity and word length effects on memory span using free recall instructions and scoring.

A few experiments have used tasks in which the lists are not restricted to small subsets of repeated items as described above. La Pointe and Engle (1990) contrasted performance on repeatedly sampled lists with performance on lists in which words were new on every trial. They contrasted recall of lists of short and long words and manipulated concurrent articulation. They replicated the effect of word length and concurrent articulation on lists from small subsets of words: Short words were better recalled than were long words, and this advantage was removed by concurrent articulation. The word length effect was also obtained when lists were composed of new words on every trial, but the word length effect survived concurrent articulation. This result is hard to reconcile with any current theory of short-term working memory (Neath \& Nairne, 1995).

We can now consider the effects of limited and unlimited word sets to construct phonologically similar and dissimilar lists. The findings are that the phonological similarity effect is significant but smaller when words are new on every trial because the dissimilar lists are less well recalled than are dissimilar lists chosen from a small word set (Coltheart, 1993a). In contrast to the results with the word length manipulation, concurrent articulation removed the phonological similarity effect for both newly sampled and limited word pool lists. It could be argued that item encoding is more difficult for long words than for short words, that fewer long words than short words can be rehearsed, and that fewer long words can be transferred to a limited-capacity output buffer. Consequently, the reduced recall for long words might arise from limits on encoding processes, rehearsal, and output storage and processing. However, when words are repeatedly sampled from a small, familiar set, item encoding might be achieved 
by registering the first letter or syllable of long words or some element smaller than the entire word. An abbreviated code is less likely to suffice when words are new and unpredictable on every trial. Thus, the word length effect might arise chiefly from rehearsal and output processes when words are repeatedly selected from a small pool. These processes are disrupted by concurrent articulation and the word length effect is removed. In contrast, when words are new on every trial, encoding processes also contribute to the word length effect, and these processes are not (or are less) disrupted by concurrent articulation; hence, a word length effect remains with concurrent articulation.

The experiments discussed above indicate that two of the major variables in short-term memory research (phonological similarity and word length) determine recall in situations less circumscribed than those of conventional short-term memory experiments in which small sets of list items are repeatedly presented. This is important because it permits comparison with other, more usual, memory research paradigms in which to-be-remembered items are unpredictable and novel. Such a situation prevails in both research on long-term episodic memory and research on memory for very briefly presented stimuli. It is the latter that is the concern of this paper.

\section{Recall of Rapidly Presented \\ Visual Sequences (RSVP)}

Since the research of Forster (1970) and Potter (1984, cited in Potter, 1993), we have known that lists shown word by word at the rate of about 10 words per second can be comprehended. Such stimuli appear to leave only fleeting memories; however, if they consist of words that form a coherent sentence, up to 12 or more items can be recalled. This contrasts with the very inferior recall of unrelated word lists shown at such fast rates (Potter, 1984, cited in Potter, 1993). Potter (1993) argued that words and pictures are capable of rapidly activating semantic and conceptual representations, along with scene and sentence parsing mechanisms, in long-term memory. These temporarily active representations can be regarded as a form of very short-term conceptual memory.

There are phenomena observed at fast rates of visual presentation that are not found at the slower rates typical of short-term memory tasks in which items are shown at the rate of 1 per second. At much faster rates of 8-10 items per second, the attentional blink (Raymond, Shapiro, \& Arnell, 1992) and repetition blindness (Kanwisher, 1987) are observed. The attentional blink refers to a reduced accuracy in the detection of a second target in a list when it occurs soon after the first target. Repetition blindness refers to reduced accuracy when reporting both occurrences of a repeated list item, with the second occurrence usually being omitted. Different forms of explanation have been offered for these two types of phenomena. The repetition blindness phenomenon is particularly interesting in that it occurs when the critical items are orthographically similar (but not identical) and when they are phonologically identical but differ orthographically (Bavelier
\& Potter, 1992). It is also interesting in that the task demand is similar to that in short-term memory experiments in which subjects are asked to recall the list shown but free recall scoring criteria are used. Furthermore, concurrent articulation had no effect on either recall or repetition blindness with lists shown at $117 \mathrm{msec}$ per item. It has been argued that rehearsal is not possible at these fast rates of presentation (Bavelier \& Potter, 1992).

Even if rehearsal proceeds faster than the rates of overt speech as discussed earlier, it seems reasonable to claim that presentation rates of $8-10$ items per second are too fast for rehearsal. For visually presented lists to be rehearsed, the words must be recognized, their phonological forms must be retrieved, and inner speech forms must be generated. It does not seem likely that there is sufficient time for these processes to occur when words are presented at rates of 8-10 per second.

Support for this argument is provided by the evidence of phonological and orthographic repetition blindness exhibited when stimuli are successively presented at fast rates (Bavelier \& Potter, 1992). People have difficulty in establishing a second phonological representation of an item that is phonologically identical to an earlier stimulus. This difficulty rapidly diminishes over a period of about $0.5 \mathrm{sec}$, and it does not occur at the much slower presentation rates of standard short-term memory tasks. If the phonological codes that are the basis for short-term memory recall cannot readily be established at rates of 8-10 words per second, how is recall achieved and why does phonological repetition blindness occur? The fact that repetition blindness and recall were unaffected by concurrent articulation in Bavelier and Potter's study supports the view that recall of rapidly presented stimuli is not mediated by the phonological codes arising in shortterm memory tasks as a consequence of rehearsal.

The aim of Experiments 1 and 2 was to establish the temporal conditions under which phonological coding of the form found in short-term memory tasks would be manifest. Past research has shown that phonologically similar lists are less accurately recalled than are dissimilar lists when lists of 5 or 6 items are shown at rates of 0.5-1.0 sec (Baddeley, 1966, 1986; Conrad, 1964). Experiment 1 investigated whether phonological similarity affected recall when lists were presented at both fast and more conventional short-term memory rates. The experiments reported in this paper used large word pools from which stimuli were selected. The rationale for this procedure was that phonological similarity effects have been found with such lists and that the conditions would more closely resemble those that occur when lists of words, pictures, and sentences are shown at fast rates.

\section{EXPERIMENT 1}

\section{Method}

Subjects. Thirty-six subjects, consisting of first-year undergraduates and postgraduate students at Macquarie University, participated.

Stimulus materials. The phonologically similar and dissimilar list words used in Coltheart (1993a) were used, along with additional comparable words. The pools of similar and dissimilar words con- 
sisted of 62 words and 75 words, respectively. The words were all three letters long and consisted of CVC combinations. Similar words all contained the letter $a$ and began with 17 different consonants and ended with 8 different consonants (e.g., map, cat, map, pat). There is a limited pool of three-letter words in which the letter $a$ is appropriately pronounced, which are not proper names, slang, or very rare words. Thirteen words were used twice so that 15 lists of 5 words per list could be constructed for each level of phonological similarity. Dissimilar words matched the similar ones in mean word frequency (23 and 20, respectively, in Kučera \& Francis, 1967) and used all the vowels and a more varied set of consonants (e.g., mop, vet, cow, pen, $d a y$, etc.). Within a list, no pair of words shared both their vowel and final consonant. Words were sampled without replacement from these sets so that no word appeared more than once within a list.

Apparatus and Procedure. Lists of 5 words were presented at three rates: 114,243 , and $500 \mathrm{msec}$ per word. The lists were shown, in the center of the screen, one word at a time with no interstimulus interval. Similar and dissimilar lists were shown in a different random order to each subject in blocks of 10 lists $(5$ similar and 5 dissimilar lists). Each block was shown at one of the three presentation rates, and the order of blocks and assignment of lists to blocks was counterbalanced. Thus, each subject saw 30 lists (5 similar and 5 dissimilar lists at each of the three rates of presentation). The stimuli were shown on an IBM PC using the DMASTR software (Forster \& Forster, 1990). Words appeared in white on a black background. The subjects were instructed to recall the list words in the order shown and to write each list on a fresh page, with word position marked in a column, in a booklet. They were told to leave positions blank when they could not recall a word since only words in correct serial position would be scored as correct. Each block of 5 similar and 5 dissimilar lists was shown in a different random order to each subject. Practice lists of similar types of words were used to introduce the task.

\section{Results}

The mean percentages of words recalled in correct order (with 95\% confidence intervals, CIs) are shown for the two types of lists and for each of the three presentation rates in Figure 1. Analyses of variance with presentation rate and list type were conducted for all the experiments reported in this paper, but the mean differences are reported with ref-

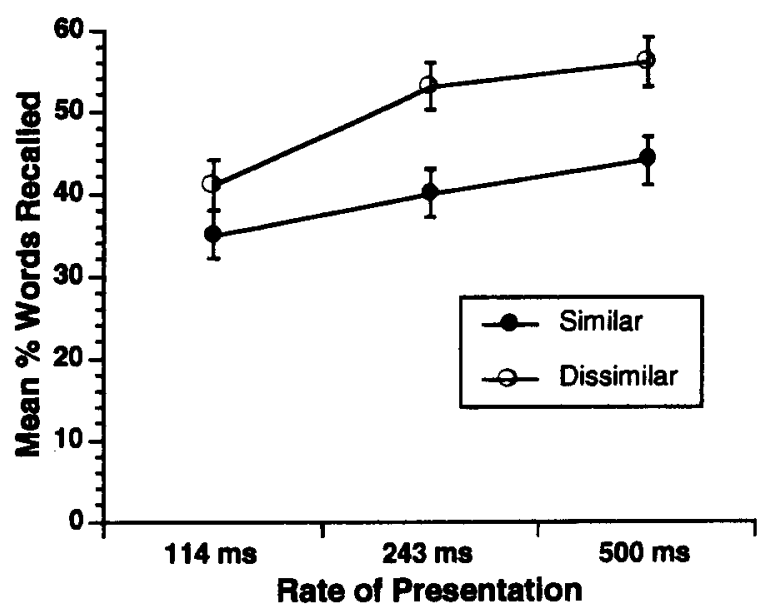

Figure 1. Mean percentages of words recalled (with $95 \%$ confidence interval error bars) from phonologically similar and dissimilar lists shown at different rates in Experiment 1. erence to $95 \%$ CIs. Phonologically similar lists were less well recalled (39.5\%) than were dissimilar lists $(50 \%$; $\mathrm{CI}=$ 1.8). Increasing presentation time improved recall from $38 \%$ at $114 \mathrm{msec}$ to $47 \%$ at $243 \mathrm{msec}$ and to $50 \%$ at $500 \mathrm{msec}(\mathrm{CI}=2.75)$. The phonological similarity effect $(6 \%)$ was significant at the $114-\mathrm{msec}$ rate $(\mathrm{CI}=2.95)$ but was smaller than it was at the slower rates $(13 \%)$.

Note that when recall was scored with order disregarded, phonological similarity still impaired recall $(49 \%$ vs. $57 \%$ correct; $C I=1.35$ ) and recall increased with slower rates of presentation from $45 \%$ to $54 \%$ to $58 \%$ from fastest to slowest rate $(\mathrm{CI}=2.43)$. Thus, the phonological similarity effect is not merely the consequence of scoring item order information.

Differences in recall as a function of phonological similarity and rate of presentation were further assessed by examining the incidence of omissions. The mean percentages of omissions are shown in Figure 2. Significantly more words were omitted in recall of similar lists $(30 \%)$ than in recall of dissimilar lists $(23 \% ; C I=1.24)$. The incidence of omissions was higher with faster rates of presentation (38\% at $114 \mathrm{msec}, 24 \%$ at $243 \mathrm{msec}$, and $19 \%$ at $500 \mathrm{msec} ; \mathrm{CI}=2.16)$.

The incidence of recall intrusions (words not shown in the list) was also examined, and the mean percentages for the various list conditions are shown in Figure 2. Analyses of intrusions indicated the following results. Phonological similarity did not significantly affect the level of intrusions. Intrusions were more frequent at slower rates of presentation $(17 \%$ at $114 \mathrm{msec}, 21.6 \%$ at $243 \mathrm{msec}$, and $23 \%$ at $500 \mathrm{msec} ; \mathrm{CI}=2.26$ ).

\section{Discussion}

The results of Experiment 1 clearly demonstrate detrimental effects of phonological similarity at rates of presentation as fast as $114 \mathrm{msec}$ per word. At this rate, the decrement produced by phonological similarity of list items was significantly lower than it was for the slower rates of 243 and $500 \mathrm{msec}$ per word. However, differences in the size of effects obtained using response probability as the dependent variable cannot be unambiguously interpreted (see Loftus, 1978).

The analysis of the recall omission data also indicates an influence of phonological similarity at even the fastest rate of presentation. When lists were phonologically similar, the subjects reported fewer items in recall than they did when lists consisted of dissimilar words. Additionally, a major consequence of fast presentation rates is a reduction in the number of words recalled. The subjects do not recall list items less accurately: They fail to recall them at all. The intrusion data support this assertion. Intrusions, which are inaccurately recalled words, were less likely to occur at the faster rates of presentation: They were found when presentation rates approximated those in standard short-term memory tasks. The results provide evidence of phonological coding for lists presented visually at rates as fast as $114 \mathrm{msec}$ per item. 


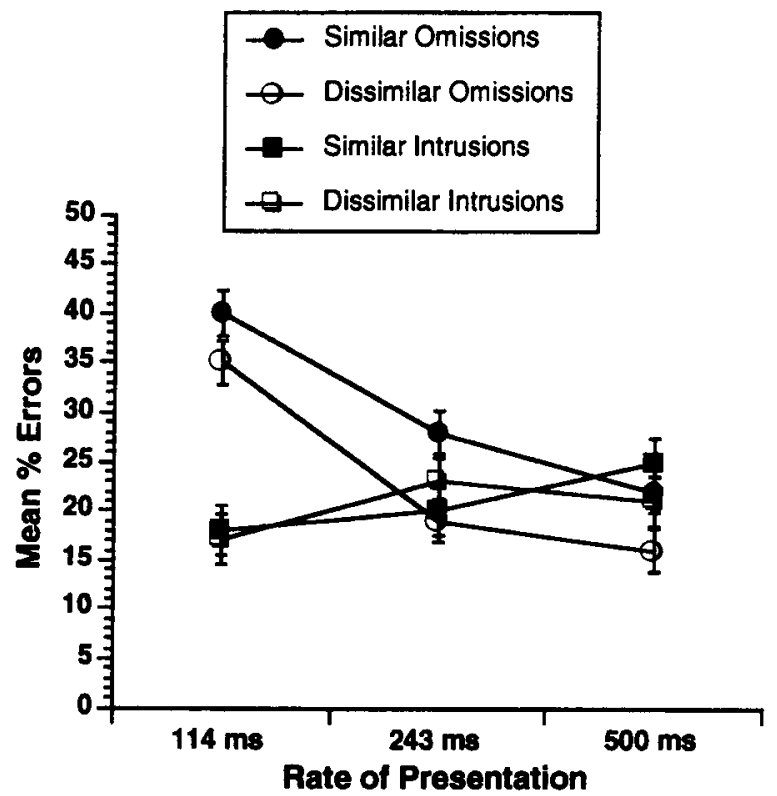

Figure 2. Mean percentages of omissions and intrusions in recall (with $95 \%$ confidence interval error bars) of phonologically similar and dissimilar lists in Experiment 1.

\section{EXPERIMENT 2}

The results of Experiment 1 show that a significant phonological similarity effect occurred at presentation rates ranging from $114 \mathrm{msec}$ to $500 \mathrm{msec}$ (the rate used in short-term memory research). Experiment 2 investigated the influence of presentation rate further and also manipulated recall instructions. Free and serial recall instructions were compared, since previous investigators have found that phonological similarity effects are confined to serial recall (Watkins et al., 1974; Wickelgren, 1965).

It has been asserted that phonological similarity effects are caused by the requirement to recall items in their order of presentation, and evidence of this was presented by Watkins et al. (1974) using somewhat longer lists of 7 words. In contrast, Schiano and Watkins (1981) found phonological similarity decreased memory span in both serial and free recall conditions using lists of words and pictures of objects with similar or dissimilar names.

\section{Method}

Subjects. Thirty-six new subjects from the same subject pool as that for Experiment 1 participated in Experiment 2. Half the subjects were given serial recall instructions, and half were given free recall instructions.

Stimulus materials. The same lists were used as those in Experiment 1 .

Apparatus and Procedure. The software and computer were the same as those used in Experiment 1, but the presentation rates were 114, 157, and $243 \mathrm{msec}$ per word. Again, the subjects were presented 5 similar lists and 5 dissimilar lists in a block at each rate, and they recalled a total of 30 lists. For half the subjects, ordered recall instructions were given; the remaining subjects were simply asked to write down as many list words as they could in any order. Both groups recalled each list on a new page of a small booklet. Order of presentation and list blocks was counterbalanced.

\section{Results}

In the serial recall condition, only words recalled in correct serial position were scored as correct; in the free recall condition, order was disregarded, and all correctly recalled list words were counted as correct. The mean percentages of correctly recalled words for the two conditions and the three rates of presentation are shown in Figure 3 . Recall instruction was a between-subjects factor, and presentation rate and phonological similarity were within-subjects factors.

Recall with free recall instructions and scoring (50\%) was superior to recall with serial recall $(42 \% ; \mathrm{CI}=3.53)$, but instructions did not interact with phonological similarity or presentation rate. Phonologically similar lists were less well recalled than were dissimilar lists $(42 \%$ vs. $49 \% ; \mathrm{CI}=1.48$ ). Increasing presentation time improved recall from $40 \%$ at $114 \mathrm{msec}$ per item to $46 \%$ at $157 \mathrm{msec}$ and $52 \%$ at $243 \mathrm{msec}$ per item $(\mathrm{CI}=2.06)$. The phonological similarity effect was marginal (3\%) at the 114-msec rate and increased with the slower rates to $7 \%$ at $157 \mathrm{msec}$ and $10 \%$ at $243 \mathrm{msec}$ rates $(\mathrm{CI}=2.40)$.

The recall data of the subjects given serial recall instructions were also scored using free recall criteria. When these scores were compared with those of the subjects performing with free recall instructions, no significant differences between the two instruction conditions were found. Slowing rate of presentation improved recall, and phonological similarity impaired recall for both groups, as it did in the analyses reported above.

The incidence of omissions was also recorded and analyzed for Experiment 2, and the mean percentages for the various conditions are shown in Figure 4.

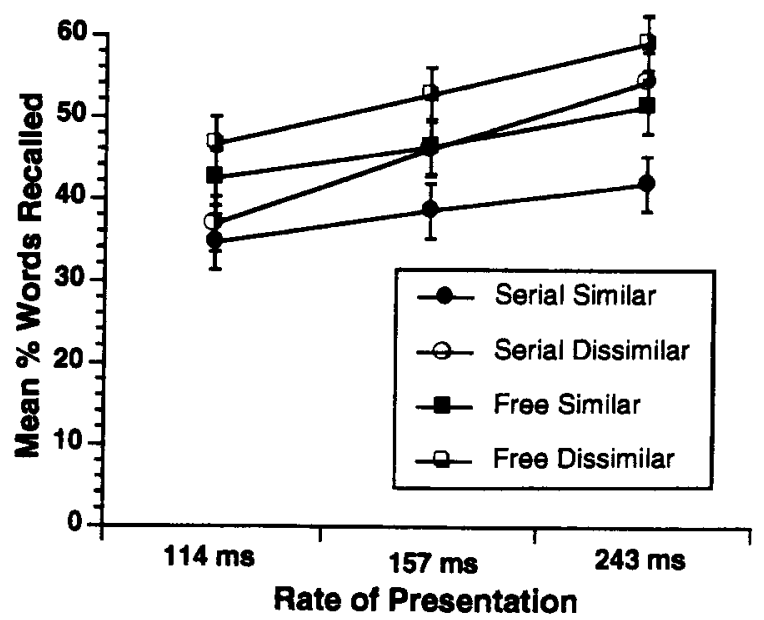

Figure 3. Mean percentages of words recalled (with $95 \%$ confidence interval error bars) from phonologically similar and dissimilar lists shown at different rates with serial and free recall instructions in Experiment 2. 


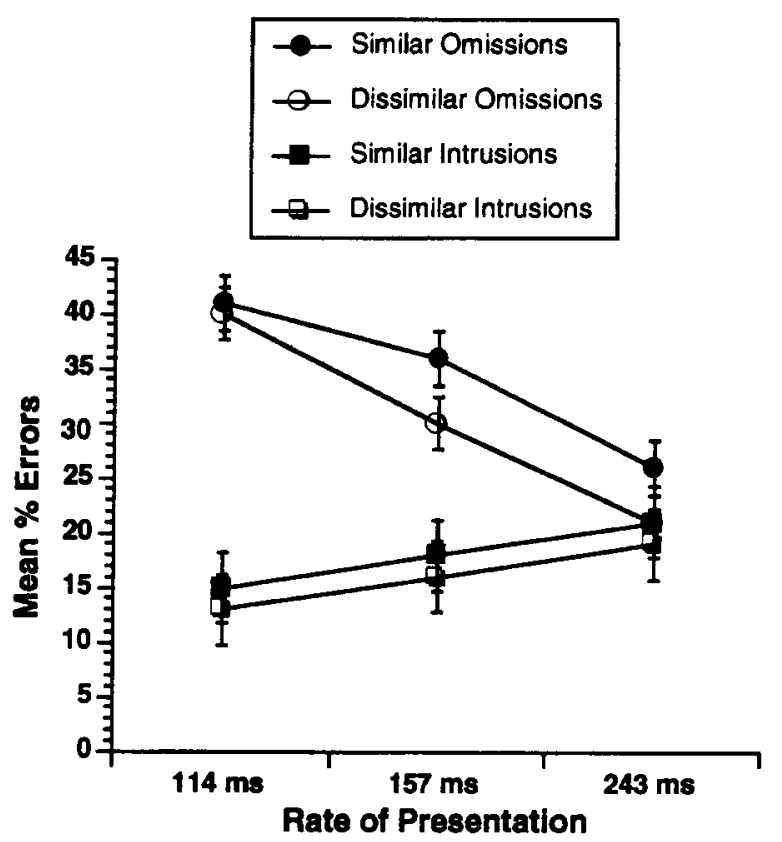

Figure 4. Mean percentages of omissions and intrusions in recall (with $95 \%$ confidence interval error bars) of phonologically similar and dissimilar lists in Experiment 2.

Recall instructions had no significant effect on the rate of omissions in recall. Phonological similarity had a substantial effect: Significantly more words were omitted during recall of similar lists (34\%) than during recall of dissimilar lists $(30 \% ; C I=1.01)$. The incidence of omissions was also higher with faster rates of presentation ( $41 \%$ at $114 \mathrm{msec}, 33 \%$ at $157 \mathrm{msec}$, and $24 \%$ at $243 \mathrm{msec}$; $\mathrm{CI}=1.64)$. There was an interaction between phonological similarity and rate: At the fastest rate $(114 \mathrm{msec}$ per word), the level of omissions did not differ significantly for similar and dissimilar lists $(41 \%$ and $40 \%$, respectively).

The incidence of recall intrusions is shown for the various conditions in Figure 4. Significantly more intrusions occurred with phonologically similar lists than with dissimilar lists $(18 \%$ and $16 \% ; \mathrm{CI}=1.21)$. Intrusions increased with slower rates of presentation from $14 \%$ to $20 \%$ $(\mathrm{CI}=1.80)$. The level of intrusions did not differ significantly as a function of recall instructions, nor did recall instruction interact significantly with any other factor.

\section{Discussion}

The results of Experiment 2 are similar to those of Experiment 1 in showing that phonological similarity impaired recall at much faster rates of presentation than those used in short-term memory research. As found in Experiment 1, the results show that the effect of phonological similarity was smaller for faster rates of presentation. The difficulty in recalling phonologically similar lists was also demonstrated by a higher level of omissions in recall for these lists. The incidence of omissions was reduced with slower presentation rates, as it was in Experiment 1.

The results of Experiment 2 also show that the phonological similarity effect is not dependent on the requirement for item and order information, and is found with free recall instructions. In fact, the instructions did not interact significantly with either phonological similarity or rate of presentation. The higher recall scores obtained when item order was disregarded chiefly occurred because, although words were typically recalled in presentation order, the subjects did not always appropriately indicate the location of omitted items. Thus, if Words 1,2 , and 4 were recalled, the subject did not indicate that Word 3 was missing, and he/she wrote Word 4 in the third serial position. With item and order scoring, Word 4 would be counted an error.

Experiments 1 and 2 provide evidence that phonological coding is possible even when lists are presented at rates about 6-9 times those used in short-term memory research. The effect of phonological similarity increased with slower rates of presentation, and the size of the effect $(12 \%-13 \%$ at $243-\mathrm{msec}$ presentation) was not appreciably different from that found with the standard 1 -sec presentation (14\%; Coltheart, 1993a). Thus, phonological similarity appears to influence retention both after rapid visual presentation and after the slower rates of shortterm memory tasks.

\section{EXPERIMENT 3}

As stated in the introduction, word length is also a potent influence on short-term memory recall. Short (monosyllabic) words are better recalled than are long (polysyllabic) words (Baddeley et al., 1975). The effects of word length were studied in Experiment 3 for lists presented at the fast rates used in Experiment 2. As noted earlier, large word pools were used to construct lists so that words were new on every trial. The effects of free and serial recall instructions were also investigated.

\section{Method}

Subjects. Thirty-six subjects from the same subject pool as that for Experiments 1 and 2 participated in return for course credit. Eighteen subjects were assigned to each of the two recall conditions.

Stimulus materials. Seventy-five short words and 75 long words were selected from the sets used by La Pointe and Engle (1990) in their Experiment 5. The short words were monosyllabic, and the long words were three or four syllables. The words were high in mean concreteness: 5.64 and 5.69 for short and long words, respectively (Paivio, Yuille, \& Madigan, 1968). The mean word frequencies were 66 for short words and 25 for long words (Kučera \& Francis, 1967). Fifteen lists of 5 short words and 15 lists of 5 long words were selected without replacement from the two word pools. Additional practice lists of 5 short words and 5 long words were also constructed using comparable short and long words.

Apparatus and Procedure. The computer and software used to present lists were the same as those used in the previous experiments. The lists were presented at the rates of 114,157 , and $243 \mathrm{msec}$ per word. Five short-word lists and 5 long-word lists were shown at each rate in blocks of 10 lists. Order of blocks was counterbalanced, 


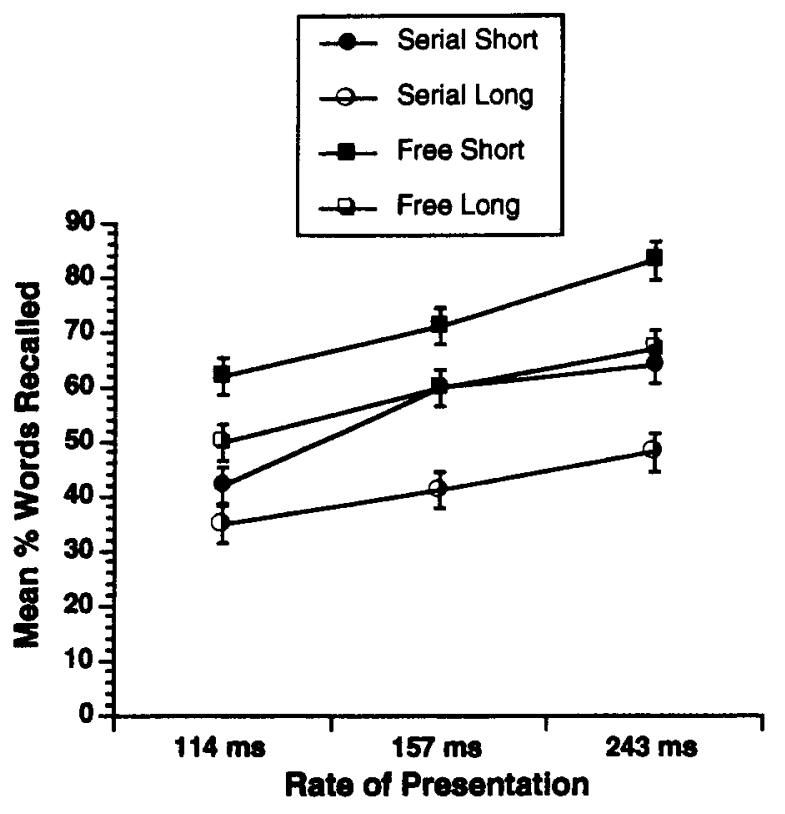

Figure 5. Mean percentages of words recalled (with $95 \%$ confidence interval error bars) from lists of short and long words shown at different rates with serial and free recall instructions in Experiment 3.

and lists within blocks were presented in a different random order to each subject. The subjects were required to recall list words in order of presentation in the serial recall condition and in any order in the free recall condition. Oral recall was used in order to reduce the time needed for output of long words, and the experimenter recorded recall.

\section{Results}

Mean percentages of words recalled at different rates of list presentation and with serial and free recall instructions are shown in Figure 5. Recall scores were significantly higher with free recall instructions and scoring than with serial recall instructions and scoring $(48 \%$ and $66 \%$; $\mathrm{CI}=4.53$ ). Short words were more likely to be recalled than were long words $(63 \%$ and $50 \% ; \mathrm{CI}=1.78)$. Recall improved with slower rates of presentation from $47 \%$ at $114 \mathrm{msec}$ to $65 \%$ at $243 \mathrm{msec}(\mathrm{CI}=2.36)$. The word length effect was smaller at the fastest rate $(9 \%)$ than at the slower rates $(14 \%$ and $16 \% ; \mathrm{CI}=2.38)$.

When item order was ignored in the serial recall condition, the levels of performance in the serial and free recall conditions were not significantly different, and the word length and presentation rate effects were both statistically reliable.

Figure 6 shows the incidence of omissions in recall for the various conditions. Significantly more omissions occurred for lists of long words $(36 \%)$ than for lists of short words $(22 \%$; $\mathrm{CI}=1.71)$. Omissions were more likely to occur with faster rates of presentation $(37.5 \%$ at $114 \mathrm{msec}$, and $20 \%$ at $243 \mathrm{msec} ; \mathrm{CI}=1.68$ ). Recall instructions did not significantly affect the rate of omissions, and no interactions were significant.
Mean percentages of recall intrusions for each condition are shown in Figure 6. Significantly more intrusions occurred with short-word lists than wiih long-word lists $(8 \%$ and $6 \% ; \mathrm{CI}=1.01)$. No other effects were significant.

\section{Discussion}

The results of Experiment 3 show clearly that lists of long words were harder to recall than were lists of short words: the word length effect. This word length effect occurred even at the fastest rate of presentation $(114 \mathrm{msec}$ $=9$ words per second) and increased with slower presentation rates. It affected performance with free recall instructions as well as with serial recall. The increase in recall at slower rates occurred for both serial and free recall instructions. These results accord with those of La Pointe and Engle (1990), who used much slower rates of presentation.

\section{EXPERIMENT 4}

The effects of phonological similarity, word length, and concurrent articulation on recall of lists presented at fast rates were investigated in Experiments 4 and 5. The lists of phonologically similar and dissimilar words used in Experiment 2 were shown using two rates of presentation $(114$ and $157 \mathrm{msec})$ in silence or when subjects were engaged in concurrent irrelevant articulation. The goal of Experiment 4 was to establish whether concurrent articulation would remove the phonological similarity effect on recall, as it does with slower rates of presentation of $500-1,000 \mathrm{msec}$. Serial position functions were also examined in both silent and articulation conditions.

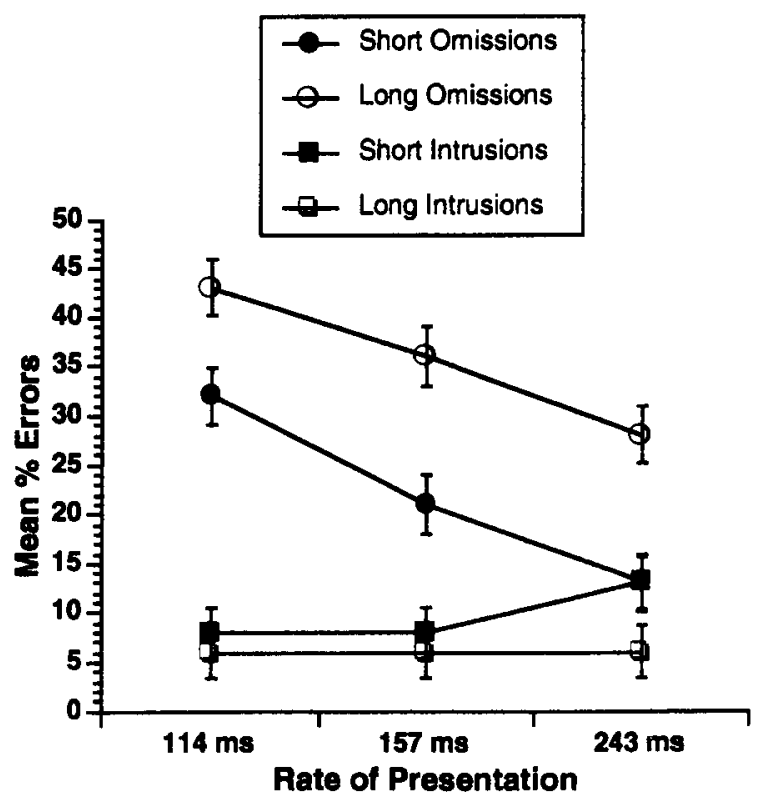

Figure 6. Mean percentages of omissions and intrusions in recall (with $95 \%$ confidence interval error bars) of short and long words in Experiment 3. 


\section{Method}

Subjects. Twenty-eight first-year psychology students, who participated in exchange for course credit, acted as subjects in Experiments 4 and 5 , with the order of experiments counterbalanced across subjects.

Stimulus materials. The words used in Experiment 2 were used to create 20 lists of 5 phonologically similar words and 20 lists of 5 dissimilar words. Thus, 38 similar words and 25 dissimilar words occurred in two lists, and the remaining words were presented once only. A practice task of similar and dissimilar words was also constructed.

Apparatus and Procedure. The apparatus and procedure were the same as those used in the previous experiments, and recall was written in booklets. The subjects were given serial recall instructions as in Experiment 1. During the concurrent articulation condition, the subjects were asked to count repeatedly from 1 to 5 during list presentation and were prompted if they slowed down. They were given practice in the articulation task and were required to count quite rapidly. Two presentation rates of 114 and $157 \mathrm{msec}$ per word were used.

\section{Results}

Mean percentages of words recalled as a function of list type, rate, and articulation condition are shown in Figure 7. Phonological similarity reduced recall $(29 \%$ for similar lists, and 33\% for dissimilar lists; $\mathrm{CI}=1.07$ ). Recall was superior at the slower $157-\mathrm{msec}$ rate than at the $114-\mathrm{msec}$ rate $(33 \%$ vs. $29 \%$; $\mathrm{CI}=1.73)$. Concurrent articulation reduced recall from $38 \%$ to $25 \%$ (CI $=$ 2.08). Figure 7 indicates that there was an interaction between articulation condition, rate, and list type. Phonological similarity significantly impaired recall in the silent condition at the slower $157-\mathrm{msec}$ rate where its effect was larger $(8.8 \%)$ than at the $114-\mathrm{msec}$ rate $(3.6 \%$;

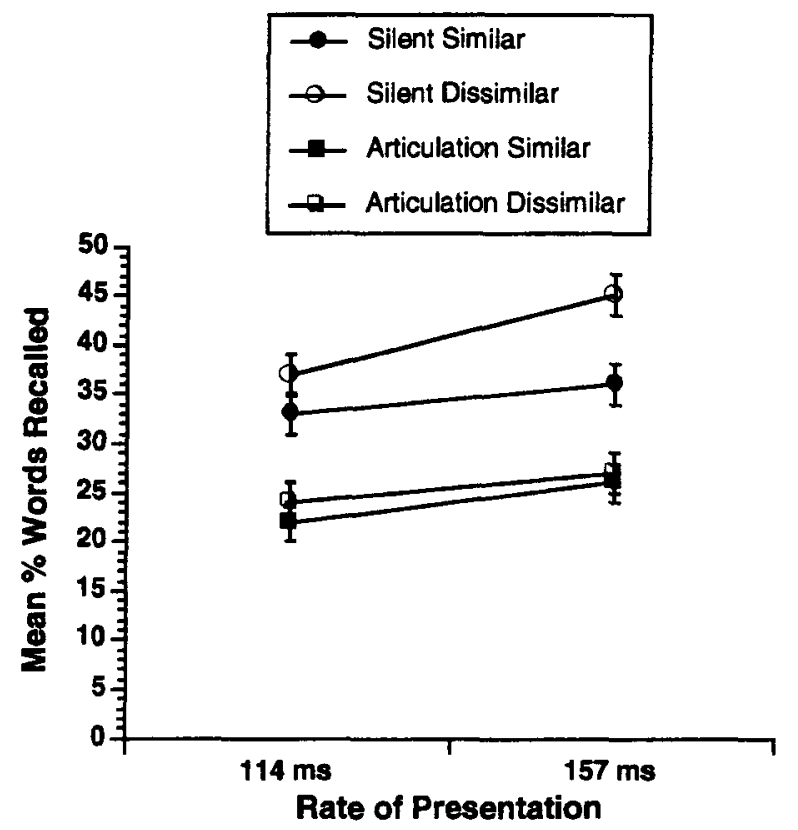

Figure 7. Mean percentages of words recalled (with $95 \%$ confidence interval error bars) from phonologically similar and dissimilar lists shown at different rates in silence or with concurrent articulation in Experiment 4.
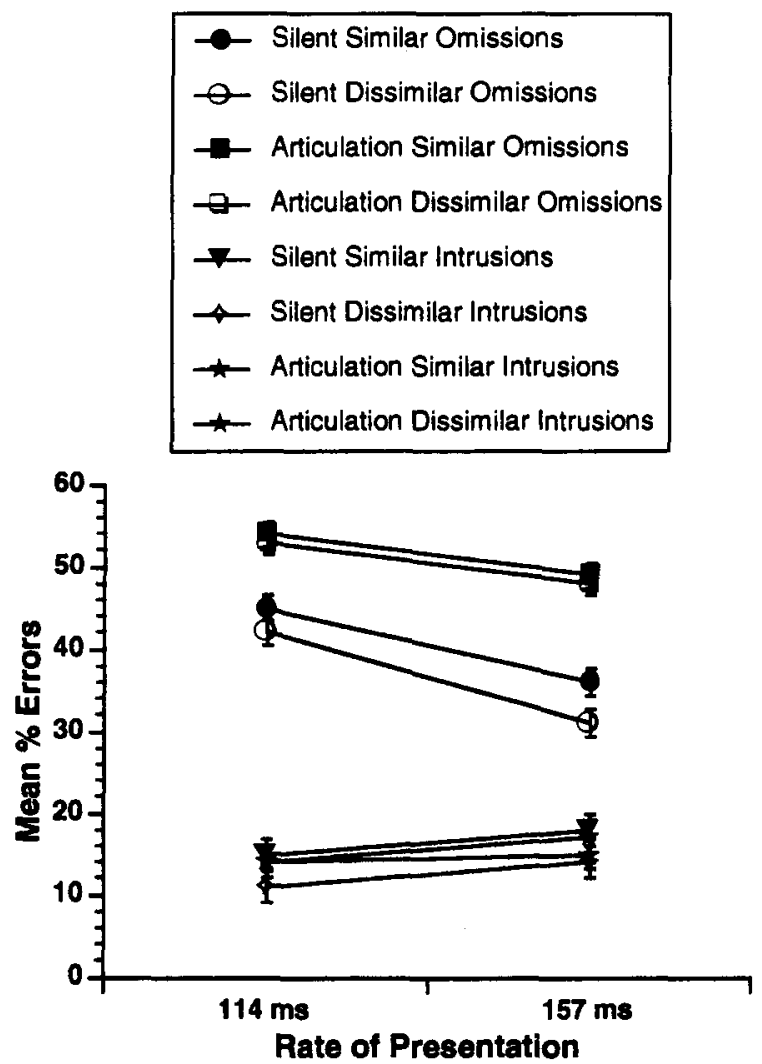

Figure 8. Mean percentages of omissions and intrusions (with $95 \%$ confidence interval error bars) in recall of phonologically similar and dissimilar words in Experiment 4.

$\mathrm{CI}=2.02$ ). In the articulation condition, similar and dissimilar list recall did not differ significantly.

When recall was scored correct disregarding order, the same pattern of effects was observed, except that the size of the phonological similarity effect was similar for both presentation rates in the silent condition ( $8 \%-9 \%)$. As in the previous analysis, the phonological similarity effect was not significant in the concurrent articulation condition.

Recall intrusions were also examined, and the mean percentages are shown in Figure 8. Intrusions were significantly more frequent for phonologically similar lists than for dissimilar lists ( $16 \%$ vs. $13 \%$; $\mathrm{CI}=1.27$ ). Intrusions were also more frequent at the slower presentation rate $(16 \%$ and $13 \% ; \mathrm{CI}=1.32)$. Concurrent articulation did not significantly affect the incidence of intrusions, and none of the variables interacted reliably.

The mean percentages of omitted words are shown in Figure 8 . The subjects were more likely to omit words for similar lists than for dissimilar lists $(46 \%$ and $43 \%$, respectively; $\mathrm{CI}=1.21$ ). Omissions were more frequent for lists shown at the faster $114-\mathrm{msec}$ rate $(49 \%$ vs. $41 \%$; $\mathrm{CI}=1.19)$ and for lists shown during articulation than for lists in the silent condition ( $51 \%$ vs. $39 \%$; $\mathrm{CI}=2.42)$. Figure 8 also indicates interactions between the variables - namely, that although omissions were less likely 
A.
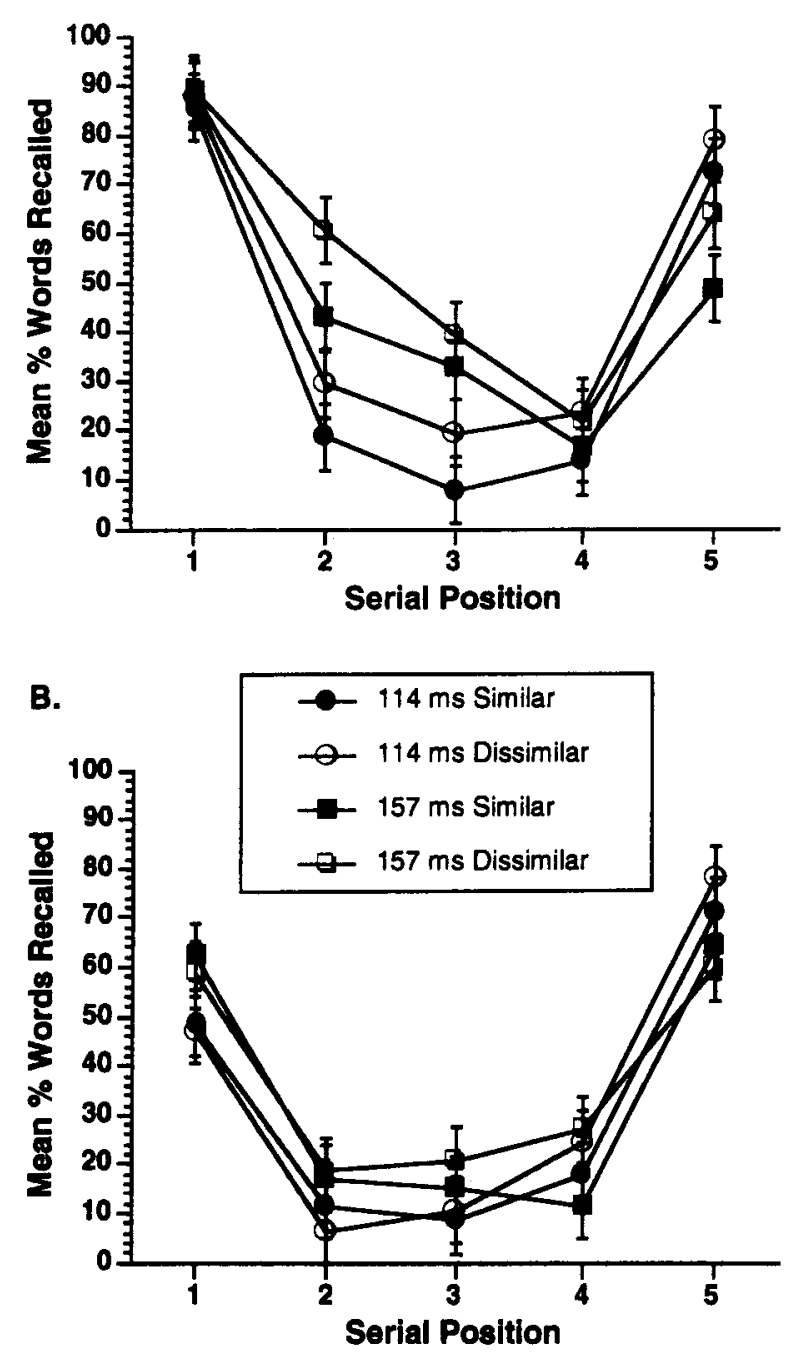

Figure 9. Mean percentages of words recalled (with $95 \%$ confidence interval error bars) as a function of serial position in Experiment 4. (A) Silent condition. (B) Concurrent articulation condition.

at the slower rate and for dissimilar lists in silent conditions, these differences were reduced in the concurrent articulation conditions.

Figure 9 presents the mean percentages of words recalled as a function of each word's serial position in the list. Both Figures $9 \mathrm{~A}$ and $9 \mathrm{~B}$ show very pronounced primacy and recency effects. The main difference between the silent and articulation conditions was a greatly reduced primacy effect in the articulation condition. The reduction in recall by concurrent articulation occurred for Serial Positions 1, 2, and 3. The recency effect was found only for the last item, and its recall was unaffected by articulation. Another consequence of concurrent articulation was a reduction in the advantage conferred by the slower $157-\mathrm{msec}$ rate of presentation. The increase in the duration of list items from 114 to $157 \mathrm{msec}$ had two main consequences. There was an increase in the recall of the second and third word in the list and a decrease in the recall of the last word in the list. Phonological similarity reduced recall mainly in Serial Positions 2, 3, and 5.

\section{Discussion}

The results of Experiment 4 confirm those of Experiments 1 and 2 in demonstrating a significant detrimental effect of phonological similarity when lists are presented in the normal silent condition. When the subjects had to engage in irrelevant concurrent articulation, recall was reduced, and there was no longer a significant effect of phonological similarity of list items. These results are typically observed when lists are presented at the much slower rates of $1,000 \mathrm{msec}$ per item in short-term memory tasks (e.g., Coltheart, 1993a; Murray, 1968).

However, there is a major difference between the results of Experiment 4 and those reported with similar list items shown at the much slower rate of $1,000 \mathrm{msec}$ per word (Coltheart, 1993a). Recall levels of dissimilar list words in the silent conditions of Experiment 4 were approximately $50 \%$ of those achieved with the $1,000-\mathrm{msec}$ rate $(83 \%$ in Coltheart, 1993a). The low levels of recall of dissimilar lists shown at 114- and 157-msec rates suggest that there are limits on the rate at which phonological and other representations can be activated and stabilized to support recall. The fact that phonological similarity further reduced recall indicates that the phonological representations established at fast rates are not qualitatively different from those generated when the slower short-term memory rates are used. Support for this suggestion is provided by the effects of irrelevant concurrent articulation in Experiment 4: It reduced recall and removed the phonological similarity effect. As noted for Experiments 1 and 2, the detrimental effects of phonological similarity and the effects of concurrent articulation are not simply due to the requirement of correct order in recall. When free recall criteria were used, the same detrimental effects of phonological similarity and concurrent articulation were observed.

The main differences between recall for lists shown at fast rates and those shown at slower rates are in the incidence of intrusions and omissions. At fast rates, recall is characterized by frequent omissions, which increase as a function of phonological similarity, presentation rate, and when subjects are articulating. At slower presentation rates, omissions are less common, and intrusions are more likely to occur. Intrusions were infrequent in Experiment 4 and were unaffected by the articulation condition. They were, however, more prevalent for phonologically similar lists and for the slower presentation rate. Intrusions are likely to be the result of combinations of phonologically similar traces, and slower rates of presentation are more likely than faster rates to increase the probability of the establishment of memory traces, even of weak or partial representations. Inspection of the intrusions indicated that many were combinations of two list words that were 
sometimes, but not always, in adjacent list positions (e.g., nag, fad to fag, or jaw, rod to raw). Others were single letter substitutions or intrusions from prior lists.

Serial position functions were also examined in Experiment 4 , and, in all conditions, strong primacy and recency effects were observed. Both effects are found with slower rates of presentation, but the recency effect with visual presentation has usually been much smaller (e.g., Avons et al., 1994; Watkins et al., 1974). The large recency effect in Experiment 4 may have been due to persistence of an iconic memory trace that may have been available during the time in which the subjects were recalling the earlier one or two list items that they were able to remember. With slower presentation, subjects recall more of the early list items, and it is unlikely that visual memory for the last item will survive the longer interval during which several earlier list items are recalled. In Experiment 4 , in the silent condition, the effect of slowing presentation rate was to increase recall of the second and third list words but to reduce recall of the last word. This result is consistent with the suggestion above that, with slower presentation, up to three words from the earlier part of the list are recalled and that a visual representation of the last word is less likely to be available after the increasing delay interval generated by the written recall of up to three words. Finally, the fact that concurrent articulation had no effect on recall of the last word is also consistent with the possibility of a visual representation for this item.

\section{EXPERIMENT 5}

Experiments 1,2, and 4 provide evidence that phonological representations of written words can be established at fast rates up to 9 words per second and that these phonological representations are disrupted by concurrent articulation. These effects have been attributed to confusion between similar traces in the phonological short-term store and the disruption of visual-to-phonological transcoding by concurrent articulation.

The word length effect on recall was also demonstrated to occur with fast rates of presentation in Experiment 3. This effect was attributed to limits on the rehearsal process (Baddeley et al., 1975), although, as noted in the introduction, this explanation has been questioned. Since rehearsal is unlikely to play a role when lists are shown at the fast rates used in Experiments 1-4, Experiment 5 investigated the effects of concurrent articulation on the recall of short and long words. Lists of short and long words were shown at 114 and $157 \mathrm{msec}$ per word in normal silent conditions and when subjects were engaged in concurrent irrelevant articulation.

\section{Method}

Subjects. The subjects $(n=28)$ who participated in Experiment 4 also acted as subjects in Experiment 5, with the order of experiments counterbalanced across subjects.

Stimulus materials. The 75 short and long words used in Experiment 3, along with 25 additional short and long ones, were used to create 20 lists of 5 short words and 20 lists of 5 long words. The mean concreteness ratings were 5.73 and 5.70 for short and long words, respectively, and their mean word frequencies were 54 and 25 , respectively. A practice task of lists of short and long words was also constructed.

Apparatus and Procedure. The apparatus and procedure were the same as those used in the previous experiments except that recall was oral rather than written, and the experimenter recorded subjects' responses. Oral recall was used to reduce output time, and serial recall was required. During the concurrent articulation condition, the subjects were asked to count repeatedly from 1 to 5 during list presentation and were prompted if they slowed down, as they were in Experiment 4.

\section{Results}

Mean percentages of words recalled in correct serial position are shown in Figure 10. Recall of lists of short words $(41 \%)$ exceeded recall of lists of long words $(36 \%$; $\mathrm{CI}=$ 1.49). The slower rate of presentation increased recall from $36 \%$ at $114 \mathrm{msec}$ to $41 \%$ at $157 \mathrm{msec}(\mathrm{CI}=1.41)$. Concurrent articulation reduced recall from $46 \%$ to $32 \%$ (CI $=$ 2.45 ). There was a significant interaction between concurrent articulation, presentation rate, and word length: Word length effects were significant only in the silent conditions and were larger for the 157-msec rate than for the 114-msec rate $(14 \%$ and $7 \%$, respectively; $\mathrm{CI}=2.48)$.

Recall was also scored without regard to order, and a similar pattern of results was found. In the articulation condition, the mean short-word list recall was $49 \%$, whereas the mean recall for lists of long words was $45 \%$, but this difference was not reliable since the $95 \%$ CIs for these means overlapped $(\mathrm{CI}=2.56)$.

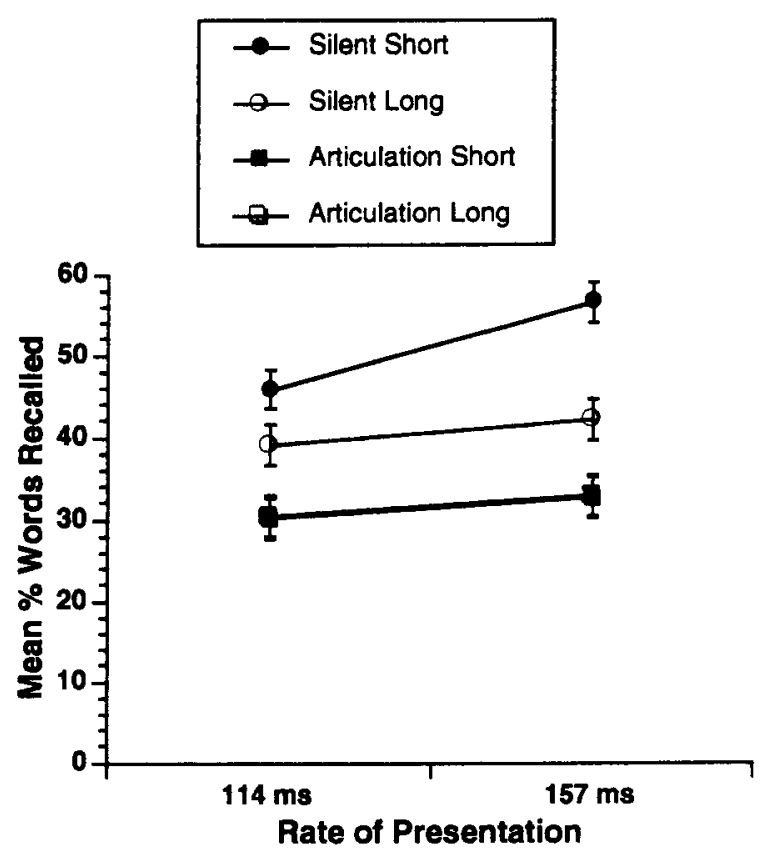

Figure 10. Mean percentages of words recalled (with $95 \%$ confidence interval error bars) from lists of short and long words shown at different rates in silence or with concurrent articulation in Experiment 5. 


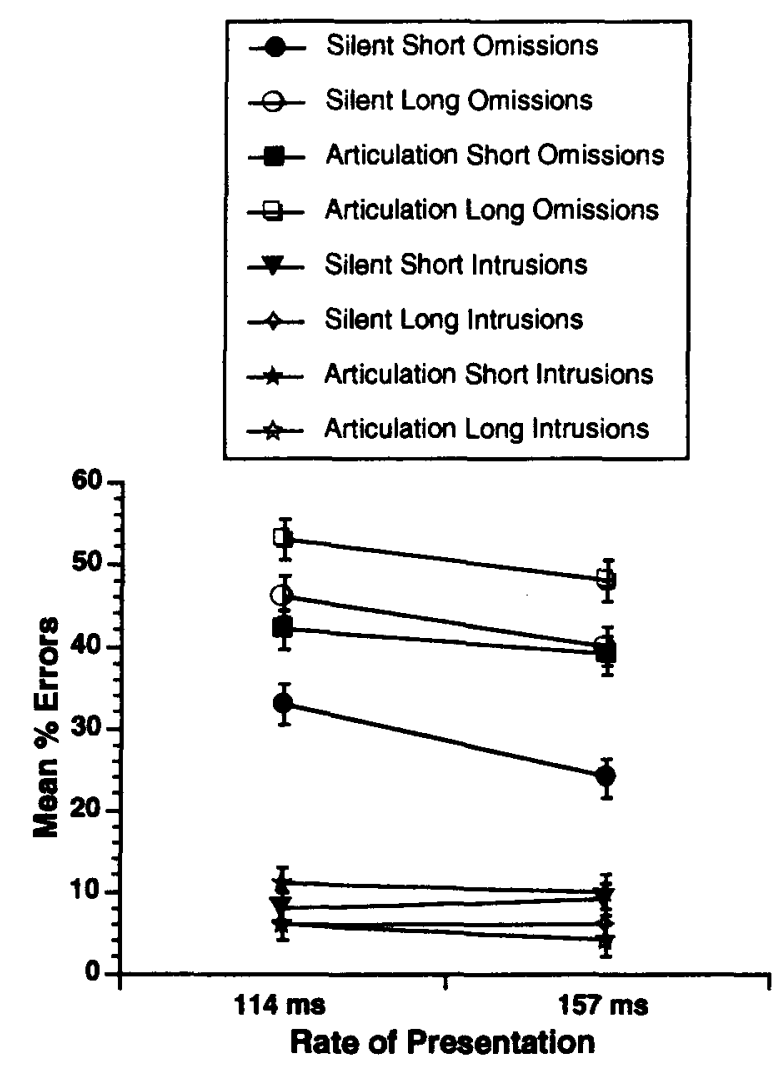

Figure 11. Mean percentages of omissions and intrusions in recall (with $95 \%$ confidence interval error bars) of short and long words in Experiment 5.

Figure 11 shows the mean percentages of omissions and intrusions in recall. The incidence of omissions was significantly higher after concurrent articulation (45\%) than in the silent condition $(36 \% ; \mathrm{CI}=1.44)$, with fast presentation rate $(43 \%$ at $114 \mathrm{msec}$, and $38 \%$ at $157 \mathrm{msec}$; $\mathrm{CI}=1.11)$ and with long words $(46 \%$ vs. $34 \% ; \mathrm{CI}=$ $1.50)$. The slower rate of presentation reduced omissions more in the silent condition (7\%) than it did in the articulation condition $(4 \% ; C I=1.4)$, and concurrent articulation increased omissions and reduced the omission difference between short and long words ( $10 \%$ vs. $14 \%$ in the silent condition; $\mathrm{CI}=2.17$ ).

Recall intrusion rates were unaffected by articulation and presentation rate but were significantly higher for short-word lists $(10 \%)$ than for long-word lists $(5 \%$; $\mathrm{CI}=1.15$ ). No other differences were significant.

Percentages of words recalled as a function of serial position in list are shown in Figure 12. As in Experiment 4, recall exhibited large primacy and recency effects, and the main effect of concurrent articulation was to reduce the primacy effect - namely, the recall of the first three words. The effect of slowing presentation rate was also similar to that of Experiment 4. Recall of Words 2 and 3 improved, and recall of Word 5 decreased. In the silent condition, recall advantage for short words was chiefly found for Serial Positions 2 and 3.

\section{Discussion}

The results of Experiment 5 show that word length affected recall in the silent condition with both 114- and $157-\mathrm{msec}$ rates of presentation and that the advantage of short over long words increased with the slower presentation rate. Concurrent articulation both reduced recall and removed the advantage of short words. These effects are both obtained with the much slower rates of 1-2 sec used in previous research on short-term memory when words are repeatedly used in lists and when item encoding is minimized. It has already been argued that rehearsal is unlikely to occur when lists are shown at the fast rates of 6 and 9 words per second used in Experiment 5. At these rates, limitations on encoding as well as on output processes are likely to cause the word length effect.

Intrusions were less frequent in recall in Experiment 5 than they were in Experiment 4. This was probably due
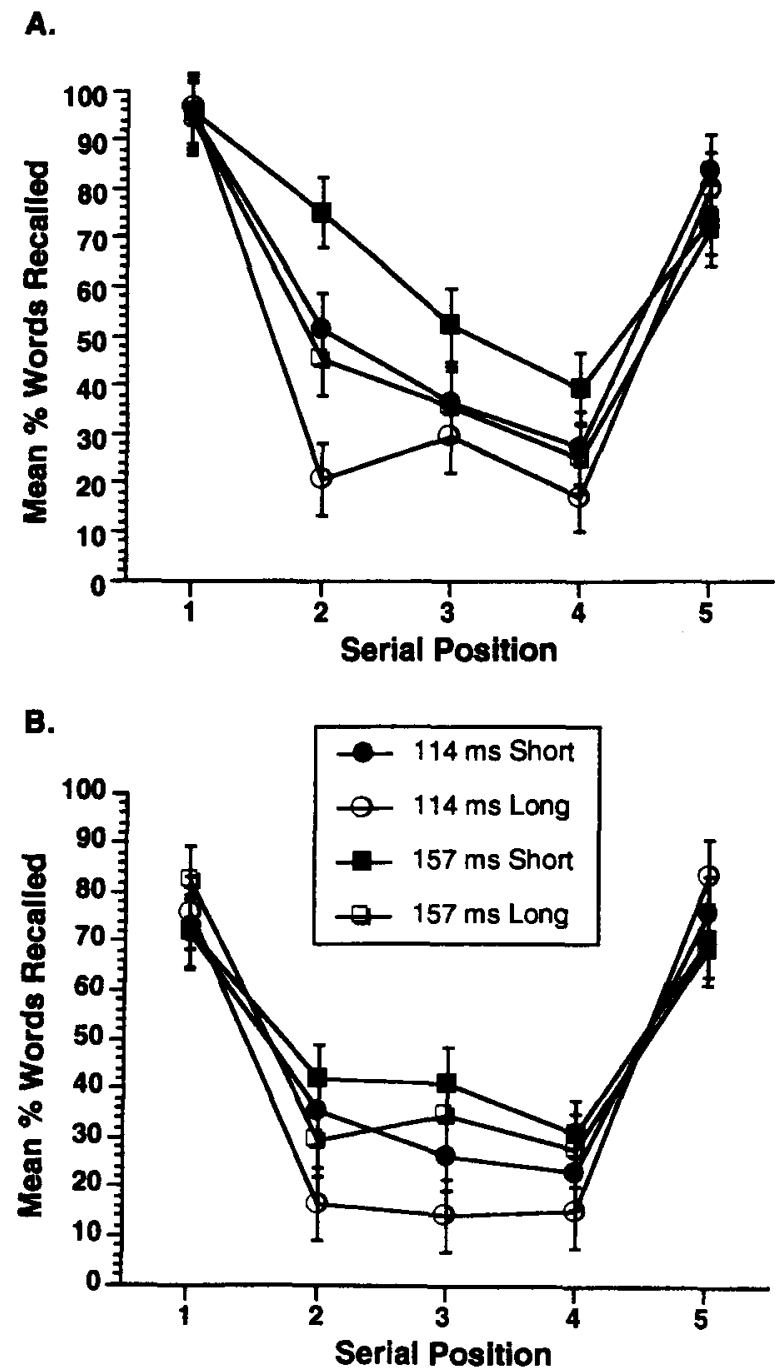

Figure 12. Mean percentages of words recalled (with $95 \%$ confidence interval error bars) as a function of serial position in Experiment 5. (A) Silent condition. (B) Concurrent articulation condition. 
to differences in the types of words used in these experiments. In Experiment 4, all word were three-letter CVC combinations and re-combinations between pairs of list words, or single-letter substitutions were likely to generate a three-letter word. In Experiment 5, even the monosyllabic short words varied more in number of letters and in the types of consonant and vowel clusters they contained. Thus, the potential real-word recombinations of pairs of list words was much lower.

However, despite the differences between the word sets used in Experiments 4 and 5, the serial position functions show many similarities. A substantial recency effect that was resistant to concurrent articulation occurred in both experiments. Slowing presentation rate extended the primacy effect to more items, and concurrent articulation reduced the primacy effect.

Possible effects of concurrent irrelevant articulation need further consideration. As noted by Gupta and MacWhinney (1995), concurrent irrelevant articulation is likely to reduce general processing capacity, reduce articulatory resources, and cause interference with phonological traces through the production of irrelevant sounds (speech). Furthermore, the auditory interference could be external (hearing one's own speech) and/or could arise internally through bone conduction. Gupta and MacWhinney found that a general (dual-task) processing difficulty, usage of articulatory resources, external auditory interference, and internally produced interference through bone conduction all contribute to concurrent articulation effects on immediate serial digit recall.

Returning to the effects of concurrent articulation on recall of rapidly presented lists, we would argue that concurrent articulation lowered overall recall because of increase in general processing demands and through the external auditory interference it causes. External auditory interference produced by heard irrelevant speech does not remove the phonological similarity effect for lists presented visually at a $1-\mathrm{sec}$ rate (Boyle \& Coltheart, 1996). Consequently, the removal of the phonological similarity effect by concurrent articulation in Experiment 4 was probably due to the disruption of phonological output processes and/or storage. It has already been argued that the word length effect with new words in every list and fast presentation is at least partly attributable to limits on encoding processes and to limits on storage capacity of a phonological output buffer. Concurrent articulation may have interfered with encoding through its general dual-task demands and through its more specific effects on output processing and storage.

As stated in the introduction, the goal of Experiments 1-5 was to investigate the temporal conditions under which phonological similarity and word length of list items affect recall. The results showed that these two variables affect recall even at the fastest rate $(114 \mathrm{msec})$ studied, although both variables have a greater influence on recall when slower rates of visual presentation are used. This indicates a continuity between processes sup- porting recall at fast RSVP rates and those of the much slower standard short-term memory tasks.

However, some phenomena, such as repetition blindness, occur at fast visual presentation rates but not at the slow (1-sec) rates used to assess short-term memory span. Thus, Bavelier and Potter (1992) found that over $90 \%$ of words were recalled from sentences of 10-13 words shown at $117-\mathrm{msec} \mathrm{RSVP}$ rates. When these sentences contained a pair of homophones (e.g., "Last night Bob ate the eight cookies in the box"), recall of the second homophone was reduced, relative to recall of an orthographically and phonologically unrelated word in control sentences. Recall of the noncritical words remained at about $90 \%$ even when subjects articulated "da da da da ..." during sentence presentation, and the extent of repetition blindness was unaffected. The absence of effects of concurrent articulation on recall in their experiment may have been partly due to the undemanding nature of the articulation of "da da da ..." and possibly to slow rates of articulation. Using continuous repetitive counting (" $1,2,3,4,5, \ldots$,), we have found a reduction in RSVP sentence recall (Coltheart, 1993b) for seven-word sentences shown at $150 \mathrm{msec}$ per word.

It has been argued that repetition blindness is an encoding phenomenon arising from token individuation (Kanwisher, 1987) or, in the case of phonological repetition blindness, registration of phonological codes in short-term memory (Bavelier \& Potter, 1992). If concurrent articulation does not interfere with the phonological encoding of individual words, then it is unlikely to affect phonological repetition blindness. The fact that it also had no effect on sentence recall indicates that semantic access and sentence parsing mechanisms do not depend on the articulatory resources that are required for concurrent articulation.

\section{CONCLUSIONS}

The experiments reported in this paper demonstrated that it is difficult to establish stable representations on which recall can be based when lists of words are presented at fast RSVP rates of $6 \mathbf{- 9}$ words per second. Recall drops to about $50 \%$ of the level attained when lists are presented at a $1-\mathrm{sec}$ rate. However, there was evidence to indicate that phonological codes were established at 9 words per second and at slower presentation rates of 4 words per second, the phonological similarity effect was comparable in magnitude to that found at the $1-\mathrm{sec}$ rate. Furthermore, concurrent articulation eliminated the phonological similarity effect, as it does with slow rates of presentation.

Word length of list items also affected recall even at the fastest rates, and the word length effect increased in magnitude with slower presentation rates. Again, concurrent articulation removed the word length effect, as it does in short-term memory tasks. These results are more striking given that they occurred when list words were new on every trial and not repeatedly selected from small famil- 
iarized sets. Thus, the effects of phonological similarity and word length are not confined to recall situations that minimize item encoding and simply require retention of order information. Moreover, these effects are equally manifest when order is not a requirement and when free recall instructions and scoring criteria are used. The findings reported in this paper indicate that phonological coding has a pervasive role in supporting item recall in immediate memory tasks using very fast presentation rates and constantly changing items. At the same time, it must be recognized that phonological representations are not the only ones supporting recall. Semantic, conceptual, and orthographic representations are also the bases of recall, which, even at the fastest rates used in these experiments, did not decrease to zero with phonologically similar words.

\section{REFERENCES}

ANDERSON, R. E. (1982). Speech imagery is not always faster than visual imagery. Memory \& Cognition, 10, 371-380.

AtKinson, R. C., \& Shiffrin, R. M. (1968). Human memory: A proposed system and its control processes. In K. Spence \& J. Spence (Eds.), The psychology of learning and motivation (Vol. 2, pp. 89-195). New York: Academic Press.

Avons, S. E., Wright, K. L., \& Pammer, K. (1994). The word length effect in probed and serial recall. Quarterly Journal of Experimental Psychology, 47A, 207-231.

BADDELEY, A. D. (1966). Short-term memory for word sequences as a function of acoustic, semantic and formal similarity. Quarterly Journal of Experimental Psychology, 18, 362-365.

BADDELEY, A. D. (1986). Working memory. Oxford: Oxford University Press.

BADDELEY, A. D., \& ANDRADE, J. (1994). Reversing the word-length effect: A comment on Caplan, Rochon and Waters. Quarterly Journal of Experimental Psychology, 47A, 1047-1054.

Baddeley, A. D., Thomson, N., \& Buchanan, M. (1975). Word length and the structure of short-term memory. Journal of Verbal Learning \& Verbal Behavior, 14, 575-589.

Bavelier, D., \& PotTer, M. C. (1992). Visual and phonological codes in repetition blindness. Journal of Experimental Psychology: Human Perception \& Performance, 18, 134-147.

Boyle, R., \& ColthearT, V. (1996). Effects of irrelevant sounds on phonological coding in reading comprehension and short-term memory. Quarterly Journal of Experimental Psychology, 49A, 398-416.

CAPLAN, D., \& WATERS, G. (1994). Articulatory length and phonological similarity in span tasks: A reply to Baddeley and Andrade. Quarterly Journal of Experimental Psychology, 47A, 1055-1062.

ColThEart, V. (1993a). Effects of phonological similarity and concurrent irrelevant articulation on short-term-memory recall of repeated and novel word lists. Memory \& Cognition, 21, 539-545.

Coltheart, V. (1993b, November). Phonological codes, repetition blindness and printed sentence comprehension. Paper presented at the 34th Annual Meeting of the Psychonomic Society, Washington, DC.

Coltheart, V., Avons, S. E., \& Trollope, J. (1990). Articulatory suppression and phonological codes in reading for meaning. Quarterly Journal of Experimental Psychology, 42A, 375-399.
ConRad, R. (1964). Acoustic confusion in immediate memory. British Journal of Psychology, 55, 75-84.

Forster, K. I. (1970). Visual perception of rapidly presented word sequences of varying complexity. Perception \& Psychophysics, 8 , 215-221.

FORSTER, K. I., \& FORSTER, J. C. (1990). DMASTR display system: Laboratory software for mental chronometry [Computer software]. Tucson: University of Arizona.

GUPTA, P., \& MACWHINNEY, B. (1995). Is the articulatory loop articulatory or auditory? Re-examining the effects of concurrent articulation on immediate serial recall. Journal of Memory \& Language, 34, 63-88.

HENRY, L. A. (1991). The effects of word length and phonemic similarity in young children's short-term memory. Quarterly Journal of Experimental Psychology, 43A, 35-52.

KANWISHER, N. G. (1987). Repetition blindness: Type recognition without token individuation. Cognition, 27, 117-143.

KUČERA, H., \& FrANCIS, W. N. (1967). Computational analysis of presentday American English. Providence, RI: Brown University Press.

LA PoINTE, L. B., \& ENGLE, R. W. (1990) Simple and complex word spans as measures of working memory capacity. Journal of Experimental Psychology: Learning, Memory, \& Cognition, 16, 1118-1133.

LANDAUER, T. K. (1962). Rate of implicit speech. Perceptual \& Motor Skills, 15, 646.

LoFTUS, G. R. (1978). On interpretation of interactions. Memory \& Cognition, 6, 312-319.

MACKAY, D. G. (1981). The problem of rehearsal or mental practice. Journal of Motor Behaviour, 13, 274-285.

Marshall, P. H., \& CarTwright, S. A. (1978). Failure to replicate a reported implicit/explicit speech equivalence. Perceptual \& Motor Skills, 46, 1197-1198.

Marshall, P. H., \& CarTwright, S. A. (1980). A final (?) note on implicit/explicit speech equivalence. Bulletin of the Psychonomic Society, 15, 409.

MURRAY, D. J. (1968). Articulation and acoustic confusability in shortterm memory. Journal of Experimental Psychology, 78, 679-684.

NeATH, I., \& NaIRNE, J. S. (1995). Word-length effects in immediate memory: Overwriting trace decay theory. Psychonomic Bulletin $\& R e-$ view, 2, 429-441.

Paivio, A., Yuille, J. C., \& Madigan, S. A. (1968). Concreteness, imagery and meaningfulness. Journal of Experimental Psychology Monographs, 76(1, Pt. 2), 1-25.

POTTER, M. C. (1993). Very short-term conceptual memory. Memory \& Cognition, 21, 156-161.

Raymond, J. E., Shapiro, K. L., \& ARnell, K. M. (1992). Temporary suppression of visual processing in an RSVP task: An attentional blink? Journal of Experimental Psychology: Human Perception \& Performance, 18, 849-860.

Schiano, D. J., \& Watkins, M. J. (1981). Speech-like coding of pictures in short-term memory. Memory \& Cognition, 9, 110-114.

Watkins, M. J., Watkins, O. C., \& Crowder, R. G. (1974). The modality effect in free and serial recall as a function of phonological similarity. Journal of Verbal Learning \& Verbal Behavior, 13, 430-447.

Waugh, N., \& Norman, D. A. (1965). Primary memory. Psychological Review, 72, 89-104.

WICKELGREN, W. A. (1965). Short-term memory for phonemically similar lists. American Journal of Psychology, 78, 567-574.

(Manuscript received August 8, 1996; revision accepted for publication January 24, 1997.) 